\title{
BAURAN PEMASARAN DAN STRATEGI PENGEMBANGAN AGROINDUSTRI TAHU DI KOTA BANDAR LAMPUNG
}

\author{
(Marketing Mix and Agroindustry Development Strategy of Tofu in Bandar Lampung City)
}

Mutiara Rahmah, Ali Ibrahim Hasyim, Ktut Murniati

\begin{abstract}
Jurusan Agribisnis, Fakultas Pertanian, Universitas Lampung, Jl. Prof. Dr. Soemantri Brojonegoro No. 1, Bandar Lampung, 35145.e-mail: ktut.murniati@fp.unila.ac.id
\end{abstract}

\begin{abstract}
This research aims to analyze marketing mix, the internal and external environment, and development strategy of tofu agroindustry in Bandar Lampung City. This research uses a survey method. Respondents were owner, employee, consumers, and government which is taken purposively. Technique sampling for consumers were purposive. The method of data analysis is descriptive analysis of $4 P$ (product, price, place, and promotion) and SWOT analysis. The results show that different agroindustry scales, houshold level, medium, and large, applied marketing mix differently, the mix of the product, price, place, and promotion. Futher more, the intenal environment of the agroindustry consists of product, management and funding, human resources, business location, and marketing, while the external environment consists of economic, social and culture, competitors, technology, government policy, and consumers. Development strategies of tofu agroindustry household scale, medium, and large scale are the development of tofu production because of large demand, empowerment of the labor through training on modern technology, and marketing maintenance which are already extensive.
\end{abstract}

Key words: development strategy, marketing mix, tofu

\section{PENDAHULUAN}

Indonesia merupakan negara yang berbasis pada sektor pertanian, sehingga tidak dapat dipungkiri bahwa sektor pertanian merupakan sektor yang sangat penting bagi perekonomian Indonesia. Industri kecil mempunyai peranan yang sangat besar terhadap roda perekonomian suatu negara. Salah satu kegiatan dari industri kecil (agroindustri) hasil pertanian adalah industri pengolahan. Hampir seluruh komoditas hasil pertanian di Indonesia dapat diolah, salah satunya adalah kedelai. Olahan kedelai yang paling dikenal masyarakat adalah tahu.

Kota Bandar Lampung mempunyai potensi besar sebagai tempat berkembangnya agroindustri berbasis sumber daya alam. Berdasarkan data yang diperoleh dari Primer Koperasi Produsen Tempe Tahu Indonesia Kota Bandar Lampung (2018), terdapat 272 pengrajin tahu dan tempe yang terdapat di Kota Bandar Lampung. Banyak kendala mengancam keberlangsungan usaha agroindustri tahu di Bandar Lampung antara lain terbatasnya modal, keterampilan SDM yang rendah, pemakaian teknologi yang masih sederhana, dan tingginya biaya produksi.
Tingginya harga kedelai impor juga disebabkan oleh kenaikan harga dolar, membuat harga kedelai berfluktuasi. Sistem manajemen usaha yang tradisional kurang mampu mengantisipasi perubahan dan terbatasnya wilayah pemasaran. Banyaknya pengrajin tahu di Kota Bandar Lampung menyebabkan persaingan antara pengrajin tahu semakin ketat, sehingga mendorong setiap pengrajin tahu untuk berusaha meningkatkan volume penjualan dengan menetapkan bauran pemasaran. Bauran pemasaran merupakan kombinasi dari empat variabel dalam sistem pemasaran yaitu product, place, price, dan promotion (4P).

Berdasarkan latar belakang, potensi dan prospek yang dimiliki agroindustri tahu dapat memberikan tambahan pendapatan melalui pengembangan bisnis. Kegiatan pemasaran pada agroindustri tahu dapat didukung dengan adanya penerapan bauran pemasaran yang melibatkan konsep 4P. Umumnya kemampuan bersaing dari industri-industri yang sedang mulai berkembang masih sangat lemah, sehingga perlu adanya strategi yang langsung diarahkan pada akar persoalan. Strategi yang sesuai dengan kondisi industri akan mampu meningkatkan kemampuan dan potensi yang 
dimiliki oleh industri tersebut. Penentuan strategi untuk memahami dan mengidentifikasi dapat melalui faktor internal dan eksternal. Penelitian ini bertujuan untuk mengetahui bauran pemasaran, mengetahui faktor internal dan eksternal, dan menyusun strategi pengembangan agroindustri tahu di Kota Bandar Lampung.

\section{METODE PENELITIAN}

Metode penelitian yang digunakan dalam penelitian ini adalah metode survei. Penelitian dilakukan pada agroindustri tahu yang berada di Kota Bandar Lampung, khususnya di Kelurahan Gunung Sulah, Kelurahan Way Halim Permai, dan Kelurahan Jagabaya III dengan pertimbangan daerah ini merupakan sentra agroindustri tahu di Kota Bandar Lampung. Penentuan lokasi dilakukan secara sengaja (purposive). Responden penelitian adalah pemilik agroindustri yang digunakan untuk menganalisis bauran pemasaran. Responden pemilik, karyawan, konsumen, dan pemerintah digunakan untuk menganalisis strategi pengembangan. Pemilihan responden ditentukan secara sengaja (purposive). Masing-masing kelurahan diambil satu agroindustri untuk kebutuhan penelitian.

Berdasarkan jumlah tenaga kerja yang dimiliki, agroindustri tahu terbagi menjadi skala rumah tangga dan menengah. Karakteristik agroindustri skala rumah tangga yaitu jumlah tenaga kerja kurang dari 4 orang dan memiliki modal yang sangat terbatas, sedangkan agroindustri skala menengah jumlah tenaga kerja sekitar 20-90 orang dan memiliki modal yang cukup besar (Sajo, 2009). Responden skala rumah tangga yaitu agroindustri tahu Bapak Teguh, jumlah karyawan 2 orang, produksi per hari $60,00 \mathrm{~kg}$, lama berusaha yaitu 8 tahun, dan berada di Kelurahan Gunung Sulah. Responden skala menengah yaitu agroindustri tahu Bapak Agus dan Bapak Supratikno, jumlah karyawan 20 dan 46 orang, produksi per hari 1.000 dan $1.350,00 \mathrm{~kg}$, lama berusaha yaitu 25 dan 28 tahun, dan berada di Kelurahan Way Halim Permai dan Jagabaya III.

Data yang dikumpulkan dalam penelitian terdiri dari data primer dan data sekunder. Pengumpulan data dilakukan pada bulan Januari 2019. Metode analisis untuk menjawab tujuan pertama adalah analisis deskriptif kualitatif yaitu menganalisis bauran pemasaran menggunakan variabel 4P terdiri dari produk (product), harga (price), tempat (place), dan promosi (promotion). Metode analisis untuk menjawab tujuan ke dua adalah matriks
IFAS (Internal Factor Analysis Summary) dari lingkungan internal dan EFAS (Eksternal Factor Analysis Summary) dari lingkungan eksternal. Metode analisis untuk menjawab tujuan ke tiga adalah analisis SWOT.

\section{HASIL DAN PEMBAHASAN}

\section{Karakteristik Responden}

Responden penelitian ini berjumlah 19 orang yang terdiri dari 3 orang pemilik, 6 orang karyawan, 9 orang konsumen dan 1 orang perwakilan Dinas Perindustrian Kota Bandar Lampung. Responden pemilik, karyawan dan konsumen memiliki tingkat pendidikan yang rendah (tidak sekolah dan SD), menengah (SMP), dan tinggi (SMA dan Sarjana). Umur responden agroindustri tahu skala rumah tangga dan menengah termasuk dalam kelompok umur produktif yaitu antara 22-60 tahun. Menurut Badan Pusat Statistik (2014), pendapatan responden agroindustri tahu skala rumah tangga dan menengah berada pada golongan pendapatan sedang yaitu jika pendapatan rata-rata antara Rp1.500.000,00 sampai Rp2.500.000,00 per bulan. Penelitian ini sejalan dengan Sabam, Eliza dan Restuhadi (2015), dimana karakteristik responden berada pada umur produktif dan pendapatan berada pada golongan pendapatan sedang.

\section{Bauran Pemasaran}

\section{Produk (Product)}

Menurut Kotler dan Keller (2009), produk adalah segala sesuatu yang ditawarkan ke pasar untuk memenuhi keinginan atau kebutuhan. Rata-rata jenis tahu yang diproduksi adalah tahu putih. Ukuran produk tahu yang dihasilkan berbeda-beda mulai dari yang paling kecil sampai paling besar. Hal ini menunjukkan skala usaha menentukan jenis produk dan ukuran tahu yang dihasilkan untuk dipasarkan kepada konsumen. Berdasarkan hasil penelitian, produk dan ukuran tahu yang dihasilkan dapat dilihat pada Tabel 1 .

Agroindustri tahu skala rumah tangga dan menengah, sudah menggunakan merek dagang untuk produk tahu putih dan kuning yaitu dengan menggunakan nama pemilik agroindustri. Bentuk kemasan yang digunakan adalah plastik putih bening dengan merek yang berbeda-beda. Kelebihan produk tahu skala rumah tangga adalah tidak mudah hancur dan tidak mudah basi, dikarenakan tahu yang dihasilkan adalah tahu bungkus yang teksturnya lebih padat. 
Tabel 1. Jenis produk dan ukuran tahu di agroindustri skala rumah tangga dan menengah

\begin{tabular}{cll}
\hline $\begin{array}{c}\text { Skala } \\
\text { Agroindustri }\end{array}$ & Jenis Produk Tahu & $\begin{array}{c}\text { Ukuran Produk } \\
\text { Tahu }\end{array}$ \\
\hline Rumah tangga & $\begin{array}{l}\text { Tahu putih } \\
\text { bungkus }\end{array}$ & $9 \times 9 \mathrm{~cm}$ \\
Menengah & $\begin{array}{l}\text { Tahu putih dan } \\
\text { kuning potong, }\end{array}$ & $\begin{array}{l}11 \times 11 \mathrm{~cm}, 9 \times 9 \mathrm{~cm}, \\
\end{array}$ \\
& tahu puth & $12 \times 15 \mathrm{~cm}$, \\
& bungkus serta tahu & $11 \times 13 \mathrm{~cm}$, \\
& bulat & $12 \times 12 \mathrm{~cm}$, \\
& & $11 \times 11 \mathrm{~cm}$, \\
& & $10 \times 10 \mathrm{~cm}, 8 \times 8 \mathrm{~cm}$ \\
\hline
\end{tabular}

Kelebihan produk tahu skala menengah adalah tidak menggunakan bahan kimia, pengawet, dan pewarna buatan, diproduksi dengan higienis, dan memiliki sertifikat Lembaga Pengkajian Pangan, Obat-obatan, dan Kosmetika Majelis Ulama Indonesia (LPPOM MUI). Masa keawetan produk tahu dapat bertahan sampai 3 hari dari proses produksi. Warna tahu yang dihasilkan adalah tahu warna putih dan tahu warna kuning.

Produk tahu banyak diminati oleh konsumen, karena memiliki cita rasa yang enak dan lembut. Rasa enak dan lembut ditimbulkan karena pada saat produksi tidak menggunakan bahan pengawet. Hanya menggunakan garam sebagai perasa gurih, kunyit pewarna makanan, dan sekau (Glucono Delta Lactone), agar tahu yang dihasilkan lebih kenyal dan padat. Berdasarkan hasil penelitian ini, agroindustri tahu skala rumah tangga belum menggunakan teknologi yang modern, dikarenakan masih menggunakan tungku dan kayu untuk kegiatan produksi. Agroindustri skala menengah sudah menggunakan teknologi yang modern, dengan menggunakan pelet kayu yang berasal dari janjangan kosong kelapa sawit atau dikenal dengan nama pelet biomasa sebagai bahan bakar, lalu dialiri minyak atau bensin, maka terjadilah pembakaran di dalam mesin dan menghasilkan panas yang akan disalurkan melalui pipa-pipa untuk proses pemasakan dan penggumpalan tahu.

\section{Harga (Price)}

Menurut Kotler dan Kellen (2009), harga adalah jumlah uang yang harus dibayar pelanggan untuk memperoleh produk. Harga yang ditawarkan agroindustri tahu skala rumah tangga adalah metode berdasarkan harga di daerah sekitar atau harga pesaing, sedangkan agroindustri tahu skala menengah adalah metode berdasarkan biaya produksi dan harga pasar. Agroindustri tahu skala rumah tangga dan menengah terdapat perbedaan harga yang diberikan antara konsumen dan pedagang pengecer. Agroindustri tahu skala rumah tangga dan menengah juga memberikan selisih harga. berdasarkan ukuran tahu. Harga produk tahu di tingkat konsumen dan pedagang pengecer dapat dilihat pada Tabel 3.

Cara pembayaran yang diterapkan agroindustri tahu skala rumah tangga dan menengah berbedabeda. Agroindustri tahu skala rumah tangga tidak menerapkan potongan harga, dikarenakan harga yang diberikan sudah murah dan sesuai dengan kualitas tahu yang diberikan. Agroindustri tahu skala menengah menerapkan potongan harga jika terdapat masalah dari pengiriman atau dari produk itu sendiri. Jika kerusakan itu parah, maka potongan harganya sebesar setengah harga, tetapi jika kerusakannya biasa saja, maka hanya dikurangi potongan harga plastik.

\section{Tempat (Place)}

Menurut Kotler dan Kellen (2009), tempat meliputi kegiatan agroindustri yang membuat produk tersedia bagi pelanggan sasaran. Berdasarkan hasil penelitian, saluran distribusi yang digunakan oleh ketiga agroindustri tahu adalah sama yaitu terdapat 2 jenis saluran:

a. Produsen $\rightarrow$ Konsumen Akhir

b. Produsen $\rightarrow$ Pedangan Pengecer $\rightarrow$ Konsumen

Lokasi penjualan satu tempat dengan lokasi produksi, sehingga tidak ada biaya tambahan untuk biaya transportasi. Agroindustri skala rumah tangga tidak memiliki angkutan untuk mendistribusikan produk tahu, karena pedagang pengecer langsung mengambil ke rumah, sedangkan agroindustri skala menengah menggunakan mobil Grand Max untuk mendistribusikan produknya.

Tabel 2. Lokasi pemasaran produk tahu

\begin{tabular}{|c|c|}
\hline $\begin{array}{l}\text { Skala } \\
\text { Usaha }\end{array}$ & Lokasi Pemasaran \\
\hline $\begin{array}{l}\text { Rumah } \\
\text { tangga }\end{array}$ & $\begin{array}{l}\text { Pasar Natar, Pasar Untung Suropati, Pasar } \\
\text { Pancasila, Pasar Panjang, Pasar Sukarame, dan } \\
\text { Pasar Karang Anyar }\end{array}$ \\
\hline Menengah & $\begin{array}{l}\text { Pasar Panjang, Pasar Gintung, Pasar Perumnas } \\
\text { Way Halim, Pasar Way Kandis, Pasar Koga, } \\
\text { Pasar Tugu, Pasar Sukarame, Pasar Jati Mulyo, } \\
\text { Rumah Sakit Advent, Urip Sumoharjo, Belleza, } \\
\text { Graha Husada Supermarket Chandra. Selain } \\
\text { itu, pemasaran juga memasuki pasar di Provinsi } \\
\text { Lampung seperti Pasar Metro, Pasar Pringsewu, } \\
\text { Pasar Bakauheni, dan luar Provinsi Lampung } \\
\text { yaitu pasar di Palembang. }\end{array}$ \\
\hline
\end{tabular}


Tabel 3. Harga produk tahu agroindustri skala rumah tangga dan menengah di tingkat konsumen dan pedagang pengecer

\begin{tabular}{|c|c|c|c|c|c|}
\hline $\begin{array}{l}\text { Skala } \\
\text { Usaha }\end{array}$ & $\begin{array}{l}\text { Jenis } \\
\text { Tahu }\end{array}$ & $\begin{array}{c}\text { Ukuran } \\
\text { Tahu }\end{array}$ & $\begin{array}{c}\text { Harga } \\
\text { Konsu- } \\
\text { men } \\
\text { (per } \\
\text { potong) }\end{array}$ & $\begin{array}{c}\text { Harga } \\
\text { Pedagang } \\
\text { Pengecer } \\
\text { (per } \\
\text { potong) }\end{array}$ & $\begin{array}{c}\text { Selisih } \\
\text { Harga } \\
\text { (per } \\
\text { potong) }\end{array}$ \\
\hline $\begin{array}{l}\text { Rumah } \\
\text { tangga }\end{array}$ & $\begin{array}{l}\text { Tahu } \\
\text { putih }\end{array}$ & $\begin{array}{l}9 \times 9 \\
\mathrm{~cm}\end{array}$ & $\begin{array}{l}\mathrm{Rp} \\
500,-\end{array}$ & $\operatorname{Rp~400,-~}$ & $\operatorname{Rp} 100,-$ \\
\hline $\begin{array}{l}\text { Mene- } \\
\text { ngah }\end{array}$ & $\begin{array}{l}\text { Tahu } \\
\text { putih, } \\
\text { tahu } \\
\text { kuning } \\
\text {, dan } \\
\text { tahu } \\
\text { bulat }\end{array}$ & $\begin{array}{r}11 \mathrm{x} 11 \\
\mathrm{~cm}, \\
9 \mathrm{x} 9 \mathrm{~cm}, \\
15 \times 15 \mathrm{~cm} \\
12 \mathrm{x} \\
13 \mathrm{~cm}, \\
11 \mathrm{x} \\
13 \mathrm{~cm}, \\
12 \mathrm{x} \\
12 \mathrm{~cm}, \\
11 \mathrm{x} \\
11 \mathrm{~cm}, \\
10 \mathrm{x} \\
10 \mathrm{~cm}, \\
8 \times 8 \mathrm{~cm}\end{array}$ & $\begin{array}{l}\text { Rp } \\
\text { 300,- } \\
\text { Rp } \\
600,- \\
\text { Rp } \\
400,- \\
\text { (tahu } \\
\text { bulat), } \\
\text { Rp } \\
200,- \\
\text { Rp } \\
250,- \\
R p \\
\text { 300,- } \\
\text { Rp } \\
350,- \\
R p \\
400,- \\
R p \\
450,- \\
R p 500\end{array}$ & $\begin{array}{l}\text { Rp 220,- } \\
\operatorname{Rp} 450,- \\
\text { Rp 325,- } \\
\text { (tahu } \\
\text { bulat), } \\
\text { Rp 150,- } \\
\text { Rp 200,- } \\
\text { Rp 250,- } \\
\text { Rp 300,- } \\
\text { Rp 350,- } \\
\text { Rp 400,- } \\
\text { Rp 450,- }\end{array}$ & $\begin{array}{l}\text { Rp } \\
80,- \\
\text { Rp } \\
150,- \\
\text { Rp } \\
75,- \\
\text { Rp } \\
50,- \\
\text { Rp } \\
50,- \\
\text { Rp } \\
50,- \\
\text { Rp } \\
50,- \\
\text { Rp } \\
50,- \\
\text { Rp } \\
50,- \\
\text { Rp } \\
50,-\end{array}$ \\
\hline
\end{tabular}

Agroindustri skala rumah tangga dan menengah untuk lokasi pemasarannya berbeda-beda, sehingga tidak ada persaingan penjualan, dikarenakan lokasi penjualan yang berbeda-beda. Lokasi pemasaran kedua agroindustri dapat dilihat pada Tabel 2.

\section{Promosi (Promotion)}

Promosi berarti aktivitas yang menyampaikan manfaat produk dan membujuk pelanggan membelinya. Berdasarkan hasil penelitian, agroindustri tahu skala rumah tangga dan menengah belum melakukan promosi. Produk tahu dikenal masyarakat hanya melalui personal selling atau dari mulut ke mulut.

\section{Analisis Lingkungan Internal}

Analisis lingkungan internal adalah faktor-faktor yang berasal dari dalam agroindustri yang mempengaruhi keberadaan agroindustri, baik secara langsung maupun tidak langsung. Faktor internal terdiri dari produk, manajemen dan pendanaan, SDM, lokasi usaha, dan pemasaran. Matriks faktor internal untuk kekuatan (strength) dapat dilihat pada Tabel 4 dan 6.
Tabel 4. Matriks faktor internal untuk kekuatan agroindustri tahu skala rumah tangga

\begin{tabular}{llllll}
\hline Komponen & Kekuatan & Bobot & Rating & Skor & Rangking \\
\hline Produk & $\begin{array}{l}\text { Produk yang } \\
\text { dihasilkan } \\
\text { berkualitas }\end{array}$ & 0,12 & 4,00 & 0,49 & 1,00 \\
$\begin{array}{l}\text { Manajemen } \\
\text { dan }\end{array}$ & $\begin{array}{l}\text { Sudah } \\
\text { dilakukan } \\
\text { Pendanaan } \\
\text { penerapan } \\
\text { manajemen } \\
\text { dan pencatatan } \\
\text { keuangan } \\
\text { dengan baik }\end{array}$ & 0,09 & 3,00 & 0,29 & 4,00 \\
Sumber & $\begin{array}{l}\text { Keterampilan } \\
\text { yang baik } \\
\text { Daya }\end{array}$ & 0,11 & 3,00 & 0,34 & 2,00 \\
Manusia & $\begin{array}{l}\text { telah dimiliki } \\
\text { SDM }\end{array}$ & & & & \\
Lokasi & $\begin{array}{l}\text { Lokasi usaha } \\
\text { mudah } \\
\text { dijangkau }\end{array}$ & 0,08 & 3,00 & 0,23 & 5,00 \\
Psaha & & & & \\
\hline & $\begin{array}{l}\text { Produk tahu } \\
\text { sudah } \\
\text { dipasarkan } \\
\text { dengan baik } \\
\text { dan diminati } \\
\text { tidak hanya } \\
\text { masyarakat } \\
\text { umum, tetapi } \\
\text { juga rumah } \\
\text { sakit dan } \\
\text { supermarket }\end{array}$ & 0,11 & 3,00 & 0,31 & 3,00 \\
\hline Total Kekuatan & 0,52 & & 1,67 & \\
\hline
\end{tabular}

Berdasarkan Tabel 4, diketahui bahwa dari 5 komponen internal, kekuatan yang paling besar adalah komponen produk dengan skor 0,49 dan rating 4,00, dimana produk yang dihasilkan berkualitas dan menjadi kekuatan dari agroindustri tahu skala rumah tangga. Hasil penelitian ini sejalan dengan Siregar dan Wati (2014) dimana kekuatan yang dimiliki adalah komponen produk yaitu kualitas tahu baik.

Matriks faktor internal untuk kelemahan (weakness) agroindustri tahu skala rumah dan menengah dapat dilihat pada Tabel 5 dan 7 . Berdasarkan Tabel 5, diketahui bahwa dari 5 komponen faktor internal, kelemahan yang paling besar adalah komponen manajemen dan pendanaan dengan skor 0,29 dan rating 3,00, dimana pembukuan mengenai pengeluaran dan penerimaan belum ditulis secara tertib dan rapi. Hal ini menjadi kelemahan bagi agroindustri tahu skala rumah tangga. Pemilik tidak dapat membandingkan kondisi usahanya pada saat ini dengan tahun-tahun yang sebelumnya, sehingga pemilik tidak dapat mengetahui apakah agroindustri tersebut mengalami kenaikan atau penurunan. 
Tabel 5. Matriks faktor internal untuk kelemahan (weakness) agroindustri tahu skala rumah tangga

\begin{tabular}{|c|c|c|c|c|c|}
\hline Komponen & Kelemahan & Bobot & Rating & Skor & Rangking \\
\hline Produk & $\begin{array}{l}\text { Variasi } \\
\text { produk kurang } \\
\text { beragam dan } \\
\text { belum } \\
\text { dikemas } \\
\text { dengan baik }\end{array}$ & 0,11 & 2,00 & 0,21 & 2 \\
\hline $\begin{array}{l}\text { Manajemen } \\
\text { dan } \\
\text { Pendanaan }\end{array}$ & $\begin{array}{l}\text { Pembukuan } \\
\text { mengenai } \\
\text { pengeluaran } \\
\text { dan } \\
\text { penerimaan } \\
\text { belum ditulis } \\
\text { secara tertib } \\
\text { dan rapi }\end{array}$ & 0,09 & 3,00 & 0,29 & 1 \\
\hline $\begin{array}{l}\text { Sumber } \\
\text { Daya } \\
\text { Manusia }\end{array}$ & $\begin{array}{l}\text { Tenaga kerja } \\
\text { berpendidikan } \\
\text { rendah }\end{array}$ & 0,09 & 2,00 & 0,19 & 4,00 \\
\hline $\begin{array}{l}\text { Lokasi } \\
\text { Usaha }\end{array}$ & $\begin{array}{l}\text { Lokasi usaha } \\
\text { tidak mudah } \\
\text { dijangkau }\end{array}$ & 0,08 & 2,00 & 0,16 & 5,00 \\
\hline Pemasaran & $\begin{array}{l}\text { Tidak ada } \\
\text { kegiatan } \\
\text { promosi untuk } \\
\text { pengembangan } \\
\text { agroindustri } \\
\text { tahu } \\
\text { selanjutnya }\end{array}$ & 0,10 & 2,00 & 0,21 & 3,00 \\
\hline \multicolumn{2}{|c|}{ Total kelemahan } & 0,48 & & 1,07 & \\
\hline
\end{tabular}

Dapat dilihat pada Tabel 6, diketahui dari 5 komponen, kekuatan yang paling besar adalah pemasaran dengan skor 0,46 dan rating 4,00, dimana produk tahu sudah dipasarkan dengan baik dan diminati berbagai kalangan masyarakat umum. Berdasarkan Tabel 7, diketahui bahwa dari 5 komponen faktor internal, kelemahan yang paling besar adalah komponen sumber daya manusia dengan skor 0,34 dan rating 3,00, dimana tenaga kerja berpendidikan rendah.

\section{Analisis Lingkungan Eksternal}

Analisis lingkungan eksternal merupakan faktorfaktor yang berasal dari luar agroindustri baik berupa faktor peluang maupun faktor ancaman. Faktor eksternal terdiri dari ekonomi, sosial dan budaya, teknologi, pesaing, kebijakan pemerintah, dan konsumen. Matriks faktor eksternal untuk peluang (opportunities) agroindustri tahu skala dan menengah dapat dilihat pada Tabel 8 dan 10 . Tabel 8, diketahui bahwa dari 5 komponen eksternal, peluang yang paling besar adalah komponen ekonomi, sosial dan budaya dengan skor 0,41 dan rating 4,00, dimana tahu diminati oleh berbagai lapisan masyarakat dan menjadi peluang bagi agroindustri tahu skala rumah tangga.
Tabel 6. Matriks faktor kekuatan (strength) agroindustri tahu skala menengah

\begin{tabular}{|c|c|c|c|c|c|}
\hline Komponen & Kekuatan & Bobot & Rating & Skor & Rangking \\
\hline Produk & $\begin{array}{l}\text { Produk yang } \\
\text { dihasilkan } \\
\text { berkualitas }\end{array}$ & 0,08 & 4,00 & 0,32 & 2,00 \\
\hline $\begin{array}{l}\text { Manajemen } \\
\text { dan } \\
\text { Pendanaan }\end{array}$ & $\begin{array}{l}\text { Sudah } \\
\text { dilakukan } \\
\text { penerapan } \\
\text { manajemen } \\
\text { dan } \\
\text { pencatatan } \\
\text { keuangan } \\
\text { dengan baik }\end{array}$ & 0,08 & 3,00 & 0,24 & 5,00 \\
\hline $\begin{array}{l}\text { Sumber } \\
\text { Daya } \\
\text { Manusia }\end{array}$ & $\begin{array}{l}\text { Keterampilan } \\
\text { yang baik } \\
\text { telah dimiliki } \\
\text { sumber daya } \\
\text { manusia }\end{array}$ & 0,08 & 3,00 & 0,24 & 4,00 \\
\hline $\begin{array}{l}\text { Lokasi } \\
\text { Usaha }\end{array}$ & $\begin{array}{l}\text { Lokasi usaha } \\
\text { mudah } \\
\text { dijangkau }\end{array}$ & 0,09 & 3,00 & 0,27 & 3,00 \\
\hline Pemasaran & $\begin{array}{l}\text { Produk tahu } \\
\text { sudah } \\
\text { dipasarkan } \\
\text { dengan baik } \\
\text { dan diminati } \\
\text { tidak hanya } \\
\text { masyarakat } \\
\text { umum tetapi } \\
\text { juga rumah } \\
\text { sakit dan } \\
\text { supermarket }\end{array}$ & 0,09 & 4,00 & 0,36 & 1,00 \\
\hline Total & Kekuatan & 0,41 & & & 1,43 \\
\hline
\end{tabular}

Tabel 7. Matriks faktor kelemahan (weakness) agroindustri tahu skala menengah

\begin{tabular}{lllllc}
\hline Komponen & \multicolumn{1}{c}{ Kelemahan } & \multicolumn{1}{l}{ Bobot } & Rating & Skor & Ranking \\
\hline Produk & $\begin{array}{l}\text { Variasi produk } \\
\text { kurang beragam } \\
\text { dan belum } \\
\text { dikemas dengan } \\
\text { baik }\end{array}$ & 0,05 & 3,00 & 0,14 & 4,00 \\
Manajemen & $\begin{array}{l}\text { Pembukuan } \\
\text { dan }\end{array}$ & 0,06 & 3,00 & 0,18 & 5,00 \\
Pendanaan & $\begin{array}{l}\text { pengeluaran dan } \\
\text { penerimaan } \\
\text { belum ditulis } \\
\text { secara tertib dan } \\
\text { rapi } \\
\text { Tenaga kerja } \\
\text { berpendidikan } \\
\text { rendah }\end{array}$ & 0,11 & 3,00 & 0,34 & 1,00 \\
$\begin{array}{l}\text { Daya } \\
\text { Manusia }\end{array}$ & & & & & \\
Lokasi & $\begin{array}{l}\text { Lokasi usaha } \\
\text { tidak mudah } \\
\text { dijangkau }\end{array}$ & 0,11 & 2,00 & 0,23 & 3,00 \\
Pemasaran & $\begin{array}{l}\text { Tidak ada } \\
\text { kegiatan promosi } \\
\text { untuk } \\
\text { pengembangan } \\
\text { tahu selanjutnya }\end{array}$ & 0,13 & 2,00 & 0,25 & 2,00 \\
\hline Total Kelemahan & 0,59 & 0,46 & & 1,14 \\
\hline
\end{tabular}


Salah satu kebutuhan masyarakat yang semakin meningkat adalah produk tahu, karena tahu makanan lauk pauk yang banyak diminati masyarakat dari berbagai kalangan.

Berdasarkan Tabel 9, diketahui ancaman yang paling besar adalah ekonomi, sosial dan budaya serta konsumen dengan skor 0,27 dan rating 1,00 dan 3,00. Hal ini menjadi ancaman bagi agroindustri tahu skala rumah tangga. Berdasarkan Tabel 10, diketahui peluang yang paling besar adalah ekonomi, sosial dan budaya dengan skor 0,33 dan rating 3,00 . Hal ini menjadi peluang bagi agroindustri tahu skala menengah.

Berdasarkan Tabel 11, diketahui ancaman yang paling besar adalah komponen konsumen dengan skor 0,31 dan rating 3,00, dimana banyaknya produk tahu lain yang ditawarkan kepada konsumen.

Tabel 8. Matriks faktor eksternal untuk peluang (opportunities) agroindustri tahu skala rumah tangga

\begin{tabular}{|c|c|c|c|c|c|}
\hline Komponen & Peluang & Bobot & Rating & Skor & Rangking \\
\hline $\begin{array}{l}\text { Ekonomi, } \\
\text { sosial dan } \\
\text { budaya }\end{array}$ & $\begin{array}{l}\text { Tahu diminati } \\
\text { oleh berbagai } \\
\text { lapisan } \\
\text { masyarakat }\end{array}$ & 0,10 & 4,00 & 0,41 & 1,00 \\
\hline Teknologi & $\begin{array}{l}\text { Adanya } \\
\text { teknologi alat } \\
\text { mesin produksi } \\
\text { yang lebih } \\
\text { efisien }\end{array}$ & 0,06 & 2,00 & 0,13 & 5,00 \\
\hline Pesaing & $\begin{array}{l}\text { Daya saing } \\
\text { produk tinggi }\end{array}$ & 0,10 & 3,00 & 0,30 & 2,00 \\
\hline Kebijakan & Adanya & 0,13 & 2,00 & 0,26 & 4,00 \\
\hline Pemerintah & $\begin{array}{l}\text { pelatihan } \\
\text { tenaga kerja } \\
\text { melalui } \\
\text { kegiatan Gugus } \\
\text { Kendali Mutu } \\
\text { (GKM) }\end{array}$ & & & & \\
\hline Konsumen & $\begin{array}{l}\text { Banyaknya } \\
\text { konsumen yang } \\
\text { menyukai } \\
\text { produk tahu, } \\
\text { karena } \\
\text { bersertifikat } \\
\text { halal dan } \\
\text { tentunya aman } \\
\text { untuk } \\
\text { dikonsumsi } \\
\end{array}$ & 0,09 & 3,00 & 0,29 & 3,00 \\
\hline \multicolumn{2}{|c|}{ Total Peluang } & 0,49 & & 1,38 & \\
\hline
\end{tabular}

Tabel 9. Matriks faktor eksternal untuk ancaman (threat) agroindustri tahu skala rumah tangga

\begin{tabular}{|c|c|c|c|c|c|}
\hline Komponen & Ancaman & Bobot & Rating & Skor & Rangking \\
\hline $\begin{array}{l}\text { Ekonomi, } \\
\text { sosial dan } \\
\text { budaya }\end{array}$ & $\begin{array}{l}\text { Kenaikan harga } \\
\text { bahan baku } \\
\text { mempengaruhi } \\
\text { biaya produksi }\end{array}$ & 0,13 & 2,00 & 0,27 & 1,00 \\
\hline Teknologi & $\begin{array}{l}\text { Perkembangan } \\
\text { teknologi sulit } \\
\text { diikuti karena } \\
\text { memerlukan } \\
\text { biaya yang cukup } \\
\text { tinggi }\end{array}$ & 0,07 & 2,00 & 0,14 & 4,00 \\
\hline Pesaing & $\begin{array}{l}\text { Banyaknya } \\
\text { pesaing sejenis } \\
\text { yang masuk ke } \\
\text { pasar }\end{array}$ & 0,08 & 2,00 & 0,15 & 3,00 \\
\hline $\begin{array}{l}\text { Kebijakan } \\
\text { pemerintah }\end{array}$ & $\begin{array}{l}\text { Kurangnya } \\
\text { pengawasan dari } \\
\text { pemerintah }\end{array}$ & 0,07 & 1,00 & 0,07 & 5,00 \\
\hline Konsumen & $\begin{array}{l}\text { Banyaknya } \\
\text { produk tahu lain } \\
\text { yang ditawarkan } \\
\text { kepada konsumer }\end{array}$ & 0,09 & 3,00 & 0,27 & $2,, 00$ \\
\hline Tota & Ancaman & 0,43 & & 0,89 & \\
\hline
\end{tabular}

Tabel 10. Matriks faktor eksternal untuk peluang (opportunities) agroindustri tahu skala menengah

\begin{tabular}{|c|c|c|c|c|c|}
\hline Komponen & Peluang & Bobot & Rating & Skor & Rangking \\
\hline $\begin{array}{l}\text { Ekonomi, } \\
\text { sosial dan } \\
\text { budaya }\end{array}$ & $\begin{array}{l}\text { Tahu diminati } \\
\text { oleh berbagai } \\
\text { lapisan } \\
\text { masyarakat }\end{array}$ & 0,11 & 3,00 & 0,33 & 1,00 \\
\hline Teknologi & $\begin{array}{l}\text { Adanya } \\
\text { teknologi alat } \\
\text { mesin produksi } \\
\text { yang lebih } \\
\text { efisien }\end{array}$ & 0,11 & 3,00 & 0,32 & 2,00 \\
\hline Pesaing & $\begin{array}{l}\text { Daya saing } \\
\text { produk tinggi }\end{array}$ & 0,11 & 3,00 & 0,32 & 3,00 \\
\hline $\begin{array}{l}\text { Kebijakan } \\
\text { pemerintah }\end{array}$ & $\begin{array}{l}\text { Adanya } \\
\text { ipelatihan TK } \\
\text { melalui } \\
\text { kegiatan Gugus } \\
\text { Kendali Mutu } \\
\text { (GKM) }\end{array}$ & 0,08 & 2,00 & 0,17 & 5,00 \\
\hline Konsumen & $\begin{array}{l}\text { Banyaknya } \\
\text { konsumen yang } \\
\text { menyukai } \\
\text { produk tahu }\end{array}$ & 0,09 & 3,00 & 0,28 & 4,00 \\
\hline \multicolumn{2}{|c|}{ Total Peluang } & 0,47 & 0,50 & & 1,42 \\
\hline
\end{tabular}


Tabel 11. Matriks faktor eksternal untuk ancaman (threat) agroindustri tahu skala menengah

\begin{tabular}{|c|c|c|c|c|c|}
\hline Komponen & Ancaman & Bobot & Rating & Skor & Rangking \\
\hline $\begin{array}{l}\text { Ekonomi, } \\
\text { sosial dan } \\
\text { budaya }\end{array}$ & $\begin{array}{l}\text { Kenaikan } \\
\text { harga bahan } \\
\text { baku } \\
\text { mempengaruhi } \\
\text { biaya produksi }\end{array}$ & 0,06 & 2,00 & 0,12 & 3,00 \\
\hline Teknologi & $\begin{array}{l}\text { Perkembangan } \\
\text { teknologi sulit } \\
\text { diikuti karena } \\
\text { memerlukan } \\
\text { biaya yang } \\
\text { cukup tinggi }\end{array}$ & 0,06 & 2,00 & 0,11 & 4,00 \\
\hline Pesaing & $\begin{array}{l}\text { Banyaknya } \\
\text { pesaing sejenis } \\
\text { yang masuk ke } \\
\text { pasar }\end{array}$ & 0,11 & 2,00 & 0,22 & 2,00 \\
\hline $\begin{array}{l}\text { Kebijakan } \\
\text { pemerintah }\end{array}$ & $\begin{array}{l}\text { Kurangnya } \\
\text { pengawasan } \\
\text { dari } \\
\text { pemerintah }\end{array}$ & 0,09 & 1,00 & 0,09 & 5,00 \\
\hline Konsumen & $\begin{array}{l}\text { Banyaknya } \\
\text { produk tahu } \\
\text { lain yang } \\
\text { ditawarkan } \\
\text { kepada } \\
\text { konsumen }\end{array}$ & 0,10 & 3,00 & 0,31 & 1,00 \\
\hline \multicolumn{2}{|c|}{ Total Ancaman } & 0,53 & 0,42 & & 0,85 \\
\hline
\end{tabular}

Tabel 12. Pembobotan diagram SWOT faktor internal \& eksternal agroindustri tahu skala rumah tangga dan menengah

\begin{tabular}{|c|c|c|c|c|c|}
\hline \multirow{2}{*}{$\begin{array}{c}\text { Skala } \\
\text { Usaha }\end{array}$} & \multirow[t]{2}{*}{ Uraian } & \multicolumn{2}{|c|}{ Faktor Internal } & \multicolumn{2}{|c|}{ Faktor Eksternal } \\
\hline & & Kekuatan & Kelemahan & Peluang & Ancaman \\
\hline \multirow[t]{2}{*}{$\begin{array}{l}\text { Rumah } \\
\text { tangga }\end{array}$} & $\begin{array}{l}\text { Bobot } \\
x\end{array}$ & 1,67 & 1,07 & 1,38 & 0,89 \\
\hline & $\begin{array}{l}\text { Rating } \\
\text { Selisih }\end{array}$ & & 60 & 0, & 49 \\
\hline \multirow{2}{*}{\multicolumn{2}{|c|}{$\begin{array}{r}\text { Menengah Bobot } \\
\mathrm{x} \\
\text { Rating } \\
\text { Selisih }\end{array}$}} & 1,43 & 1,14 & 1,42 & 0.85 \\
\hline & & & 29 & 0, & 58 \\
\hline
\end{tabular}

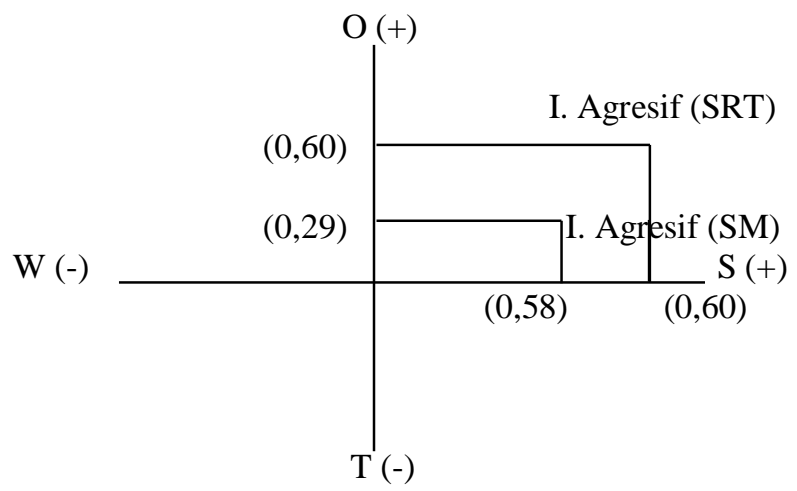

Gambar 1. Diagram SWOT faktor internal dan eksternal agroindustri tahu skala rumah tangga dan menengah

\section{Strategi Pengembangan}

Berdasarkan nilai akan dibuat diagram SWOT sumbu $\mathrm{x}$ dan $\mathrm{y}$, dapat dilihat pada Gambar 1 . Gambar 1 menunjukkan agroindustri tahu skala rumah tangga dan menengah berada pada Kuadran I artinya situasi yang sangat menguntungkan, karena memiliki peluang dan kekuatan, sehingga dapat memanfaatkan peluang yang ada secara optimal. Strategi yang harus diterapkan dalam kondisi ini adalah mendukung kebijakan pertumbuhan yang agresif. Penelitian ini sejalan dengan penelitian Sandyansyah, Rusman dan Pardani (2017) yang juga berada pada Kuadran I dengan sumbu $\mathrm{X}$ bernilai 1,80 dan sumbu $\mathrm{Y}$ bernilai 2,35 .

\section{Strategi Prioritas}

Strategi prioritas diperoleh dengan cara menyilangkan faktor internal dan eksternal yaitu SO, ST, WO, dan WT yang menghasilkan 100 strategi. Selanjutnya dilakukan pendekatan terhadap visi dan misi Dinas Perindustrian Kota Bandar Lampung. Strategi prioritas agroindustri tahu skala rumah tangga dan menengah adalah:

1. Pengembangan produksi tahu ke skala yang lebih besar, karena tahu diminati berbagai kalangan masyarakat.

2. Meningkatkan modal kerja, agar dapat memenuhi permintaan produk tahu dari konsumen yang lebih tinggi.

3. Pemberdayaan TK dengan pelatihan teknologi modern untuk pembuatan tahu.

4. Pemanfaatan lokasi agroindustri yang strategis untuk mendapatkan keuntungan yang lebih besar.

5. Mempertahankan pemasaran yang sudah cukup luas karena tahu diminati oleh berbagai lapisan masyarakat.

\section{KESIMPULAN}

Berdasarkan hasil dan pembahasan disimpulkan bahwa bauran pemasaran yang diterapkan oleh agroindustri tahu skala rumah tangga dan menengah meliputi bauran produk, harga, tempat, dan promosi yang berbeda-beda. Lingkungan internal agroindustri tahu terdiri dari produk, manajemen dan pendanaan, sumber daya manusia, lokasi usaha, dan pemasaran, sedangkan lingkungan eksternal terdiri dari ekonomi, sosial dan budaya, teknologi, pesaing, kebijakan pemerintah, dan konsumen. Strategi pengembangan agroindustri tahu skala rumah tangga dan menengah adalah pengembangan 
produksi tahu ke skala yang lebih besar, karena tahu diminati berbagai kalangan masyarakat, pemberdayaan TK dengan pelatihan teknologi modern, dan mempertahankan pemasaran yang sudah cukup luas.

\section{DAFTAR PUSTAKA}

BPS [Badan Pusat Statistik]. 2014. Upah Minimum Regional/Provinsi. http://bps.go.id/link tabledinamis/view/id917. [31 Januari 2019]

Primer Koperasi Produsen Tempe Tahu Indonesia Kota Bandar Lampung. 2018. Daftar UMK Pengrajin Tahu Tempe Kota Bandar Lampung. Bandar Lampung.

Kotler P, L Kevin dan Keller. 2009. Manajemen Pemasaran. Edisi Bahasa Indonesia. Pearson Education Asia Pte. Ltd. Dan PT Prenhallindo. Jakarta.

Sajo, D. 2009. Klasifikasi Industri. http://geografi bumi.blogspot.com/2009/10/klasifikasiindustri.html. [8 November 2018].
Sabam BM, Eliza dan F Restuhadi. 2015. Analisis bauran pemasaran jamur tiram di Kota Pekanbaru. Jurnal Jom Faperta, 2 (2) : 112. http://jom.unri.ac.id/index.php/JOMF APERTA/article/download. [31 Oktober 2018].

Sandyansyah IY, Rusman dan C Pardani. 2017. Strategi pengembangan agroindustri tahu goreng (Studi kasus pada perusahaan tahu goreng De Rifa di Desa Cisadap Kecamatan Ciamis Kabupaten Ciamis). Jurnal Ilmiah Mahasiswa AGROINFO GALUH, 4 (3) : 344-351. https://jurnal. unigal.ac.id/index.php/agroinfogaluh/articl e/downloadSuppFile. [30 Oktober 2018].

Siregar G, Salman dan L Wati. 2014. Strategi pengembangan usaha tahu rumah tangga. Jurnal Agrium, 19 (1) : 12-20. http:// download.portalgaruda.org/article.php\%3F article\%3D334529\%26val\%3D6157\%26tit le\%3DSTRATEGI\%2520PENGEMBAN GAN\% 2520USAHA\% 2520 TAHU\% 2520 RUMAH\%2520TANGGA. [30 Oktober 2018]. 